\title{
BMJ Open Quality Implementing an integrated approach to self-management support in an acute major trauma therapy team: an improvement project
}

\author{
Lucinda Hollinshead, ${ }^{1}$ Fiona Jones, ${ }^{2}$ Lucy Silvester, ${ }^{3}$ Paul Marshall-Taylor ${ }^{4}$
}

To cite: Hollinshead L, Jones F, Silvester L, et al. Implementing an integrated approach to self-management support in an acute major trauma therapy team: an improvement project. BMJ Open Quality 2019;8:e00415. doi:10.1136/ bmjoq-2018-000415

- Additional material is published online only. To view please visit the journal online (http://dx.doi.org/10.1136/ bmjoq-2018-000415).

Received 26 April 2018 Revised 12 June 2019 Accepted 17 June 2019

A Check for updates

C Author(s) (or their employer(s)) 2019. Re-use permitted under CC BY-NC. No commercial re-use. See rights and permissions. Published by BMJ.

${ }^{1}$ Bridges Self-Management, London, UK

${ }^{2}$ Centre for Health and Social Care Research, Faculty of Health, Social Care and Education, St Georges University of London and Kingston University, London, UK ${ }^{3}$ Department of Trauma and Orthopaedics, St. George's University Hospitals NHS Foundation Trust, London, UK ${ }^{4}$ Department of Trauma and Orthopaedics, St George's Hospitals and University Foundation Trust, London, UK

Correspondence to

Professor Fiona Jones;

F.Jones@sgul.kingston.ac.uk

\section{ABSTRACT}

More patients now survive multiple trauma injuries, but the level of long-term unmet needs is high. Evidence shows self-management support can improve patients ' confidence to manage these needs but traditionally this support starts post-hospital. Starting self-management support early could prepare patients and families for successful transitions from hospital. The skills and commitment of clinicians have been shown to contribute to the success or failure of self-management approaches. The aim of this project was to explore the feasibility of integrating self-management support in an acute major trauma setting by evaluating the impact of an educational intervention on clinicians' knowledge, attitudes and behaviours regarding self-management support and identifying any barriers and facilitators to integrating self-management into daily practice. Two improvement cycles were carried out over a 1-year period involving 18 allied health professionals (AHPs) in an acute major trauma centre in London, UK. An educational intervention, 'Bridges Self-Management Programme' was modified for the setting. The impact was evaluated using (1) a clinician questionnaire to evaluate knowledge and attitudes; (2) case reflection forms and (3) peer review to observe interactions to integrate self-management support. Questionnaire data were summarised and pre-training and post-training scores compared; the qualitative data from written case reflections, verbal and written feedback from training and group discussions was described and analysed thematically. The result of two improvement cycles has shown it was feasible to improve AHP's knowledge, attitudes and change behaviours regarding self-management support in the acute trauma setting, but difficult to sustain change beyond 6 months. Key barriers such as the pressure to discharge patients and support within the wider multidisciplinary team (MDT) were identified. Facilitators included the introduction of a new key-worker, to enable shared team approaches and paperwork to involve patients and families in goal setting and treatment planning. The main learning was to ensure sustainability mechanisms from the outset, engage the wider MDT in training, and integrate self-management language and principles into team processes.

\section{PROBLEM}

There are 20000 major trauma cases every year in England and by 2020 trauma will be the second greatest cause of premature death and disability. ${ }^{12}$ Trauma systems, such as the London Major Trauma system in place since 2010, provide a continuum of care for all injured patients within a geographical location. ${ }^{3}$ As a consequence, mortality and morbidity rates have improved butlong-term physical, psychological, emotional and social needs remain high. ${ }^{4}$ Access to post-hospital rehabilitation varies across the UK and existing services are often insufficient to meet the needs of people with multiple injuries. ${ }^{4}$

The National Institute for Clinical Excellence (NICE) guidelines for major trauma published in 2016 include recommendations on the management of pre-hospital and immediate hospital care but no guidance beyond these definitive lifesaving interventions. ${ }^{3}$ There is no reference to the management of emotional and psychological issues from the consequences of experiencing or recovering from major trauma. However, the generic NICE Patient Experience guidelines advocate for 'knowing the patient as an individual' to identify factors that may affect their ability to manage their own care and make decisions about self-management and lifestyle choices. ${ }^{6}$

Self-management support is often the domain of community services, as reflected in the absence of evidence about interventions in acute settings. However, interventions delivered earlier in care pathways could enable patients and families experiencing major trauma, to be more involved in their care and manage transitions from hospital to home and beyond. ${ }^{7}$ There is strong evidence in other patient groups that self-management support improves clinical outcomes, satisfaction with care, perceived quality of life ${ }^{89}$ and helps patients to achieve the outcomes important to them. ${ }^{9}$ In clinical practice, clinicians' attitudes, knowledge and behaviours regarding self-management 
support lack consistency. ${ }^{1011}$ The barriers to integrating self-management support to enable patients and families more control over their care are challenging in a highly routinised, medical environments such as acute major trauma. However, the benefits of multidisciplinary team (MDT) training in acute settings are emerging ${ }^{9} 1213$ and evaluations have shown that clinicians trained to support self-management are more satisfied with their practice. ${ }^{14}$

To evaluate the feasibility of integrating self-management support in an acute trauma setting, it was essential to gain the support for the project from senior clinicians at St George's National Health Service Foundation Trust Major Trauma Centre. While the lead allied health professional (AHP) was supportive and keen for AHP staff to be trained, nursing and medical staff were unable to attend due to staffing constraints. The trauma and orthopaedic therapy team at St George's covers 106 beds and patients are admitted under major trauma, trauma and elective (including day surgery) and plastics. Patients admitted under major trauma have a range of musculoskeletal and traumatic injuries including chest trauma, open fractures, pelvic fractures, fragility fractures and traumatic brain injury. The average length of stay is 11 days and most patients are discharged from hospital to their usual place of residence or repatriated to their local trauma or rehabilitation unit within the South West London and Surrey Trauma Network. The AHP team consisted of 20 clinicians assessing an average of 220 new patients with trauma per month. They rotate to each trauma ward on a 3 monthly basis and participate in the daily review of new admissions, orthopaedic ward round, major trauma multidisciplinary meetings and discharge planning.

An improvement project was designed to contextualise an existing stroke and brain injury self-management educational intervention for clinicians, the Bridges self-management programme (Bridges SMP), to the acute trauma setting. Bridges SMP normally comprises 10 hours of clinician training in two parts, delivered approximately 3 months apart.

The first aim of this improvement project was to evaluate and support changes in AHP's knowledge, attitudes and behaviours regarding self-management support in an acute major trauma setting within a 6-month time frame. Second, we sought to understand any barriers and facilitators to integrating self-management support into their daily practice.

\section{BACKGROUND}

Person-centred care is a critical part of health systems reform in UK and self-management support is an important component. ${ }^{9}$ Self-management approaches help people to live well with their health condition(s) and are primarily concerned with building confidence and capability to pursue quality of life goals (social and valued identities) as well as managing biomedical health. ${ }^{10}$ Self-management support is enacted through a collaborative relationship between clinicians and patients and implementation can require both parties to engage with each other in new ways of working. ${ }^{9}$ For clinicians, this can mean moving away from a paternalistic approach of 'clinician knows best', challenging potential foundations of their training ${ }^{10} 11$ and the prevailing clinical culture. ${ }^{15}$

Self-management support interventions are multi-factorial and their effectiveness depends on how they are implemented by clinicians. Implementation usually involves training teams in new ways of working and an understanding of local context is important. ${ }^{9}$ Challenges to the translation of self-management support into clinical practice have been reported including attitudes towards the intervention and the perceived time to integrate self-management support strategies into busy clinical environments. ${ }^{15} 16$ The acute clinical environment presents particular challenges compounded by pressures to discharge patients quickly in a highly medicalised environment. Patients with multiple injuries present further challenges due to the complexity of their presentation and stages of adjustment post-trauma.

The Bridges SMP is an evidence-based educational intervention that has been tested and developed in different rehabilitation settings since 2008. ${ }^{13}$ 17-20 Earlier work focused on implementation in community stroke settings but in 2013, Bridges SMP was successfully integrated into the working practices of a multidisciplinary acute stroke ward ${ }^{19}$ and in 2015 into a multidisciplinary traumatic brain injury pathway. ${ }^{13}{ }^{21}$ Studies to date have shown that Bridges SMP is experienced positively by patients and families ${ }^{1922}$ can improve patient involvement in their rehabilitation, foster greater feelings of control in patients $^{22}$ and improve clinician's confidence to support self-management. ${ }^{23}$ Projects have shown the need to engage all professional groups in the change process to facilitate a shared understanding of self-management support, support implementation and embed mechanisms that will sustain changes overtime. ${ }^{12} 132122$

\section{MEASUREMENT}

Knowledge and attitudes about self-management support and applicability to acute trauma were evaluated throughout this improvement project. The questionnaire was adapted from previous studies where self-management support was evaluated and integrated into MDTs. ${ }^{16} 19$ The questionnaire comprised 13 statements relating to AHPs' knowledge, beliefs and attitudes towards self-management support and was co-designed with four of the AHP team (one occupational therapist, a physiotherapist and two therapy technicians). Items were modified to reflect specific challenges including patients with trauma who may have cognitive impairments, be experiencing acute pain and the challenges of high patient volume and throughput.

Scoring of each questionnaire item was based on alignment with core self-management principles co-designed in 
previous work, reflecting a person-centred approach. ${ }^{16} 19$ We set a target of $\geq 50 \%$ of AHPs in alignment with self-management principles in $\geq 7 / 13$ questionnaire items to indicate a good outcome from the intervention (training package). At baseline measurement, $\geq 50 \%$ AHPs were in alignment with self-management principles in only 2/13 questionnaire items, indicating the need for an intervention to improve knowledge, beliefs and attitudes. The clinician questionnaire was administered following each improvement cycle.

Additionally, we used three further methods to explore contextual and personal issues which aided and/or hampered a self-management approach in acute trauma: (1) AHP case reflections describing accounts and experiences of integrating self-management support with a patient and families; (2) Peer review to observe clinical interactions and record against a self- management fidelity checklist used in previous research ${ }^{20}$ and (3) summary of discussions about perceived barriers and facilitators to self-management support during intervention delivery (training package).

\section{DESIGN}

The intervention (Bridges SMP) is an individualised, person-centred approach to supporting self-management delivered by trained clinicians through treatments and interactions with patients and families. Bridges is theoretically underpinned by social cognitive theory and uses the core construct of self-efficacy which relates to an individual's belief in their own capability. ${ }^{18}$ Self-efficacy is responsive to behaviourally focused interventions and is positively associated with independent mobility, activities of daily living, quality of life and negatively associated with depression. ${ }^{819}$ Clinicians support self-efficacy through promoting feelings of success, and highlighting patients' existing strengths and capabilities. Self-management is further enhanced through the integration of principles including goal-setting, problem solving, self-discovery, reflection, accessing resources, and taking-action.$^{23}$ Self-efficacy is hypothesised to be a mediator for self-management skills and for this intervention and reporting we refer to these as 'Bridges principles'.

Clinicians are trained and supported to implement Bridges' principles in collaborative ways rather than directing and leading. Facilitated through attention to clinicians' communication with patients and families, and during training, they co-design contextualised phrases and open questions to support self-management. They also reflect on and take action about how team processes such as ward rounds, goal setting, assessment methods and MDT meetings support self-management or not. This stage aims to integrate Bridges into existing organisational and team processes and is important for developing sustainability mechanisms. Bridges SMP also utilises coproduced peer-support tools (books) used by patients and families. At the time of the improvement project, there were no Bridges tools specifically for patients and families experiencing multiple injuries.

For this project, training part one was delivered as a flexible series of two half days to maximise attendance and maintain critical staffing levels. Training part two was delivered as a half day and provided the opportunity for AHPs to reflect, give feedback about their experiences of implementing Bridges SMP and develop sustainability plans.

To understand and address organisational, cultural and group factors needed for successful implementation of Bridges SMP into routine clinical practice, we used normalisation process theory (NPT) ${ }^{24} 25$ (table 1). NPT constructs provide a structure to understand how to implement and evaluate the 'normalisation' of a complex intervention with multiple influencing factors and comprise: (1) coherence (meaning and sense making about Bridges SMP); (2) cognitive participation (commitment and engagement to Bridges SMP); (3) collective action (the work clinicians do to implement Bridges SMP) and (4) reflexive monitoring (how clinicians appraise Bridges SMP).

To enhance coherence, cognitive participation and collective action, four staff members, an occupational therapist, a physiotherapist and two technical assistants, were supported to become change agents. Described as clinicians who have influence within a team, change agents can help to generate interest and support from their colleagues during an improvement project. Meetings with change agents' explored perceived clinical challenges; for example, implementation in those patients experiencing severe pain, or those with cognitive impairments and complex physical injuries. Other challenges were posed by wider MDT practices, for example a geographically disparate team, different clinical priorities and pressures to discharge patients. This information was used to adapt the intervention to the contextual challenges of the acute major trauma setting.

\section{STRATEGY}

\section{Improvement cycle one}

The aim was to deliver training on Bridges' principles to improve AHPs' knowledge, attitudes towards self-management and facilitate a change in their practice regarding integration of principles in the acute major trauma setting. We also sought to understand any barriers or facilitators to integrating Bridges SMP into daily practice. In all, 18 AHPs participated in two-part training over 3 months. In between training sessions AHPs implemented Bridges' principles into everyday practice.

We predicted that at the end of this cycle we would achieve a questionnaire outcome of $\geq 50 \%$ of AHPs in alignment with self-management principles in $\geq 7 / 13$ questionnaire items. The aim was met demonstrating $\geq 50 \%$ of AHPs in alignment with questions 1, 2, 5, 9, 10, 12 and 13 (table 2). There was a decrease in alignment with questionnaire item seven; 'the team I work in has 
Table 1 Application of NPT to project design

\begin{tabular}{|c|c|c|}
\hline NPT component & $\begin{array}{l}\text { Questions to consider in the NPT } \\
\text { framework }\end{array}$ & Example of application in this project \\
\hline $\begin{array}{l}\text { Coherence } \\
\text { (meaning and sense making by } \\
\text { clinicians) }\end{array}$ & $\begin{array}{l}\text { How is Bridges SMP different to usual } \\
\text { practice? } \\
\text { Is Bridges SMP easy to describe? } \\
\text { What benefits will Bridges SMP bring and } \\
\text { to whom? } \\
\text { How does Bridges SMP fit with the wider } \\
\text { purpose of the clinical team? }\end{array}$ & $\begin{array}{l}\text { Engagement and awareness raising of Bridges } \\
\text { SMP with trauma team in multiple meetings and } \\
\text { training opportunities to discuss what Bridges } \\
\text { SMP is, the benefits and fit with the trauma } \\
\text { setting; AHPs describing examples of changes to } \\
\text { practice following training }\end{array}$ \\
\hline $\begin{array}{l}\text { Cognitive participation } \\
\text { (commitment and engagement } \\
\text { by clinicians) }\end{array}$ & $\begin{array}{l}\text { Will AHPs think Bridges SMP is a good } \\
\text { idea? } \\
\text { Will AHPs be prepared to invest the time } \\
\text { and energy for implementation? }\end{array}$ & $\begin{array}{l}\text { Identifying and working with key change agents; } \\
\text { offering flexible training sessions to minimise } \\
\text { service disruption }\end{array}$ \\
\hline $\begin{array}{l}\text { Collective action } \\
\text { (the work clinicians do to make } \\
\text { Bridges SMP function) }\end{array}$ & $\begin{array}{l}\text { How will Bridges SMP affect the day-to- } \\
\text { day work of AHPs? } \\
\text { How compatible is Bridges SMP with } \\
\text { existing working practices? }\end{array}$ & $\begin{array}{l}\text { Contextualising training to acute major trauma; } \\
\text { emphasis on the value of integrate of self- } \\
\text { management support into interactions with } \\
\text { patients and families; support for change agents } \\
\text { between training sessions }\end{array}$ \\
\hline $\begin{array}{l}\text { Reflexive monitoring } \\
\text { (how clinicians reflect on or } \\
\text { appraise Bridges SMP) }\end{array}$ & $\begin{array}{l}\text { How are AHPs likely to view Bridges SMP } \\
\text { over time? } \\
\text { Will the effects of Bridges SMP be clear, } \\
\text { on patients and AHPs? }\end{array}$ & $\begin{array}{l}\text { Clinician questionnaires pre-training and post- } \\
\text { training; training evaluation forms; sharing stories } \\
\text { of successes and challenges of Bridges SMP at } \\
\text { training part two; regular meetings with change } \\
\text { agents to hear about implementation efforts }\end{array}$ \\
\hline
\end{tabular}

AHPs, allied health professionals; NPT, normalisation process theory; SMP, self-management programme.

a clear method for including patients in their goals and treatment plans'. This suggests while there were changes at an individual level of practice, AHPs were less certain about how their team enacted Bridges SMP, particularly during goal setting and treatment planning. A joint decision was made to implement a second stage intervention to address the team's methods of involving patients in treatment planning and goal setting.

Table 2 Proportion of AHPs in alignment with self-management support principles at baseline and improvement cycles one and two $(n=18)$

\section{Self-management support principle}

Baseline Improvement Improvement

$\begin{aligned} & 1.1 \text { have knowledge about different ways to enhance self-efficacy in patients I work } \\ & \text { with }\end{aligned}$
(5)

2.I believe that supporting self-management is a priority in my current role
$\begin{aligned} & \text { 3.The main way I support self-management is through giving information } \\ & \text { 4.Self-management support helps patients comply with their treatment }\end{aligned}$
programmes

$\begin{array}{lllll}\text { 5.Patients with cognitive problems are often unable to self-manage } & 40 & 67 & 44 \\ \begin{array}{l}\text { 6.I believe that self-management support takes more time than usual therapy } \\ \text { treatments }\end{array} & 40 & 45 & 44\end{array}$

\begin{tabular}{|c|c|c|c|}
\hline $\begin{array}{l}\text { 7. The team I work in has a clear method for including patients in their goals and } \\
\text { treatment plans }\end{array}$ & 40 & 34 & 67 \\
\hline 8.Self-management support is difficult to deliver in an acute ward setting & 17 & 20 & 11 \\
\hline 9.I always use communication methods that facilitate patients to self-manage & 45 & 67 & 78 \\
\hline 10.I feel confident to promote self-management with orthopaedic trauma & 60 & 84 & 78 \\
\hline 11.I feel confident to promote self-management with patients with brain injury & 20 & 45 & 44 \\
\hline 12.I feel confident to support families to use different self-management strategies & 15 & 84 & 67 \\
\hline $\begin{array}{l}\text { 13.I feel confident to promote the benefits and impact of self-management to other } \\
\text { members of the MDT }\end{array}$ & 5 & 67 & 55 \\
\hline
\end{tabular}

MDT, multidisciplinary team. 


\section{IMPROVEMENT CYCLE TWO}

The aim was to facilitate a shared team approach to including patients in treatment planning and goal setting through implementing new paperwork with a small sample of patients with acute trauma. Bridges target setting and reflection pages from existing self-management tools for patients were utilised with 10 patients with major trauma (online supplementary appendix 1). The target setting pages provided space for patients to plan and record the things they want to work on and capture individual successes. The reflection pages provided an opportunity for patients to record their achievements and their own strengths and strategies. Both methods support personal mastery, a strong source of self-efficacy and Bridges' principles. AHPs presented these resources for each patient using coloured clipboards, so they could be identified by staff, patients and families at the bedside. Guidance for patients about how to use the pack was developed by LH and reviewed and edited by PM-T. Six AHPs from improvement cycle one volunteered to implement the new resources. Three AHPs had joined the major trauma team since improvement cycle one and attended a brief 2-hour educational session to understand the theory and evidence behind Bridges SMP.

Following implementation of resources AHPs gave feedback that patients had shown more engagement because goals and treatment ideas were written and expressed in their own words. AHPs recognised they needed to take a step back to understand patients' ideas and goals be less in control. Challenges to implementing the resources centred on three main issues: (1) turnover of staff, (2) limited amount of time with patients and (3) the applicability to patients who were acutely unwell.

By the end of the second cycle, we predicted to see an increase in AHPs' responses to question 7, from $34 \%$ in alignment with self-management principles at the end of improvement cycle one, to $\geq 50 \%$ in line with self-management principles. A change was demonstrated and $67 \%$ of AHPs agreed that the team has a clear method for including patients in their treatment plans and goal setting'. However, we saw a decline in 11 out of 13 questionnaire items indicating that improvements in knowledge and attitudes about self-management support gained during improvement cycle one had not been sustained throughout improvement cycle two.

There was an increase in response to question 9 'I always use communication methods that facilitate patients to self-manage'. This may indicate communication methods to support Bridges principles were being used, for example, instead of instructing patients how to transfer from bed to chair, the AHP might say 'What do you remember about how to do this from yesterday?' to support the patient to problem-solve and foster a collaborative working relationship.

\section{RESULTS}

Findings from both improvement cycles are reported here, according to the aims of the project to (1) evaluate AHP's knowledge, attitudes to self-management support in acute trauma, (2) evaluate any changes in practice and behaviours regarding self-management support and (3) to understand any barriers and facilitators to integrating self-management into their daily practice.

AHP knowledge and attitudes to self-management support in an acute major trauma setting

During improvement cycle one, the intervention was successful at improving AHPs' knowledge, attitudes and beliefs to self-management support in the acute trauma setting (table 2). Analysis of AHP's surveys $(n=18)$ showed that improvements were seen in items relating to (1) self-reported confidence to support families with self-management strategies; (2) confidence to promote the benefits and impact of self-management to other members of the MDT; (3) knowledge about ways to enhance the self-efficacy of their patients; (4) attitude towards self-management support for patients with cognitive impairments and (5) confidence to apply self-management strategies to patients with orthopaedic and brain injuries. Minimal improvements were seen in items relating to the (1) feasibility of implementing self-management in the acute setting; (2) belief that self-management support takes more time; (3) knowledge about the role of compliance with treatment programmes in self-management support and (4) consensus about the team's methods of involving patients in their goals and treatment plans.

In all but two questionnaire items (questions 7 and 9), improvements in AHP knowledge, attitudes and beliefs were not maintained at the end of improvement cycle two, approximately 6 months after the intervention was first launched. We attribute the decline to the length of time between the ends of improvement cycles one and two and absence of effective sustainability strategies to maintain changes in AHP practice. The improvement in question 7 'the team I work in has a clear method for including patients in their goals and treatment plans' corresponds to the aim of improvement cycle two. We attribute the improvement in question 9 'I always use communication methods that facilitate patients to self-manage' to indicate a possible normalisation of communication methods as a strategy to integrating self-management support.

\section{AHP changes in practice and behaviours to support self- management in an acute major trauma setting}

In all, 14 out of 18 AHPs completed case reflection forms. A thematic analysis approach was used by $\mathrm{LH}$ and FJ to code and categorise common themes across all case reflections and verbal and written feedback given in group discussions. Emerging themes reflected changes in practice and methods used to integrate Bridges SMP with a diverse number of patients including those with complex social histories (no fixed abode, non-UK nationals, recent divorce or bereavement), psychological diagnoses 
(bipolar disorder, depression, suicidal tendencies) and patients in critical care settings. While the project was based primarily on acute trauma wards, clinicians did rotate to intensive care units (ICU) and one AHP was able to apply some SM principles with a patient with multiple injuries which they felt had an impact:

'His mood improved when he was able to complete tasks then he would request to sit out of bed and try tasks without our assistance'. Physiotherapist, ICU

AHPs reported a change in the focus of therapy from directing patients, to eliciting their preferences and choices about therapy and exploring the patient's understanding of their injuries and capabilities:

'I sought their perspective more, I talked about small steps instead of goals, I focussed on building rapport, I invited them to problem solve with me and I made sessions more fun through using music or a change of scene'. Occupational Therapist, Major Trauma

'I realized just because a patient is passive doesn't mean they are not motivated, it is about the professional engaging with them early on by listening as they talk about their interests, preferences, hopes and goals'. Physiotherapist, Major trauma

There was also a perceived shift in understanding and practice about the limitations of information-giving which implies a different power balance between patient and clinician:

'Self-management isn't about us telling patients what to do it's about exploring with them'. Technical Assistant, Major Trauma

\section{AHP perceived barriers and facilitators to implementing} self-management support in an acute major trauma setting AHPs' perceived barriers to implementing Bridges SMP pre-implementation and post-implementation were captured from group discussions and summarised. Before implementation, AHPs identified the barriers of time available; other MDT members not being present in the training; systems and structures within the acute environment for example, professional hierarchies, silo working, 'the way things are always done'; pressure to discharge patients; patients in a low state of awareness; patients with cognitive impairments and rotational staff. Post-implementation, two of these barriers were not discussed at all; patients in a low state awareness and rotational staff, but most discussions focused on the potential benefit of extending the training to the entire MDT.

Post-implementation, perceived facilitators to the integration of self-management support in the context of the major trauma setting were captured and written up from training room discussions and included: to have a Bridges tool (book) specifically for patients with multiple injuries and their families; to have a process for person-centred goal setting for all patients and to measure the patient perspective on aspects of self-management support. They identified the potential of a new key-worker role in sustaining self-management support for example, through leading the goal setting process and being a single point of contact for the patient's family. Results from improvement cycle two also revealed the role of shared team paperwork as a facilitator to including patients in goal setting and treatment planning.

Data from peer observations $(n=6)$ added contextual examples relating to barriers and facilitators and aided reflection on how language could be adapted to aid self-management support. These were discussed during group sessions, and this method of feedback was encouraged as a means for ongoing learning and sustainability that could be used team-wide.

An example of an interaction observed was as follows:

1. Hi my name is.... How are you? Are you in any pain?

We'd like to have a go at walking with you today, is that $\mathrm{OK}$ ?

In this scenario the patient is not given the opportunity to question the agenda of the AHP and complies with instructions, becoming a passive recipient of care.

Feedback changed the language to:

2. Hi my name is...How are you? I'm here to see if we can have a go at walking today. How do you feel about that? What concerns do you have, if any? What difficulties do you foresee.

This interaction could take longer than the first example but staff reported the benefit of engaging the patient early in the task.

\section{Lessons and limitations}

The aim of this project was to explore the feasibility of integrating self-management support in an acute major trauma setting by evaluating the impact of an educational intervention on clinicians' knowledge, attitudes and behaviours regarding self-management support and identify any barriers and facilitators to integrating self-management into daily practice. We found that AHPs' knowledge and attitudes did change and individuals were open and conducive to integrating self-management support in an acute trauma setting following training. Case reflections, group discussions and peer observations illustrated tangible examples of change in everyday clinical practice and strategies such as joint goal setting, shared decision-making and reflection on success were integrated into therapy sessions with patients with complex major trauma.

However, improvements were not fully sustained after 6 months and despite individuals achieving some practice change, self-management support using Bridges principles were not fully integrated as a team approach. There were a number of limitations and subsequent learning which will inform future projects.

First, it had not been possible to engage medical and nursing staff in the two-part training and we recognised that different modes of delivery are required so that frontline staff can access training flexibly. However, previous work has shown the value in MDT members attending at least part of the training together; with reference to 
$\mathrm{NPT},{ }^{24}{ }^{25}$ it provides an opportunity to make collective sense of self-management (coherence), see how it will fit into their daily work (collective action) and decide how much time and energy they will invest in implementing self-management strategies (cognitive participation). AHPs perceived the structure of the acute working environment and absence of the whole MDT training as barriers to integrating and sustaining self-management support.

Second, it was important to find ways to sustain changes in clinician communication style and use of self-management principles beyond the second improvement cycle. Previous work in stroke and brain injury has shown how clinicians value brief ways to enhance self-management support through their everyday communication skills, rather than viewing the approach as an 'add-on' to current work, ideal for a busy, acute environment. ${ }^{8} 1920$ The value of co-designing a group of phrases, interactions that are contextually relevant and can become part of usual work was of value here and we recognise it is critical for the effectiveness and sustainability of self-management support strategies that they are embedded into MDT processes, for example, therapy and nursing staff working more closely together to support patients to take control of everyday tasks such as washing or dressing ${ }^{1320}$; or raising awareness of self-management support principles through an induction programme or mentoring.

We also acknowledge that the findings from this improvement project are limited only to a relatively small number of AHPs in a major trauma therapy centre and we cannot rule out the possibility of response bias, within a self-selected group. The positive change in attitudes and knowledge reported could misconstrue what is potentially only a marginal change given the small numbers. We are aware of the significant investment of time to attend training and recognise that better methods of impact evaluation at patient, team and organisational levels, could persuade managers and leaders of the benefits of staff taking time out to reflect and learn together. Data were also collected over a 6-month interval and our findings could be due to chance or random fluctuations, ideally we would have repeated data collection at more frequent intervals.

Finally, we acknowledge that patient and family involvement is a critical part of improvement projects and their involvement is a limitation in this project. Future projects should measure the impact of self-management support by capturing how involved patients feel in decisions about their care, levels of knowledge about their injuries and confidence with how to mitigate any ongoing needs once they leave hospital. Their feedback could also act as a driver for clinicians about the value of a self-management approach and whether it is advantageous for them to continue investing time and effort into its implementation. AHPs in this project also identified the potential value of a co-produced peer support tool and peer support opportunities for patients with multiple injuries that could enhance their self-management support through, for example, learning from patients who have sustained similar injuries and the strategies they are using to cope and manage. This informed a new project to co-design a self-management tool for patients with major trauma, which has since completed.

Overall, we have learnt several valuable lessons from this improvement project to integrate a self-management support intervention in acute major trauma. Primarily about the need to co-design sustainability mechanisms from the outset, especially where teams experience a high turnover of staff. Future project should ensure there are multiple methods to facilitate engagement across the whole MDT and recruitment of change agents from across different staff grades (senior staff and support workers) to ensure sustainability beyond the project life.

In addition, while this project did not measure the impact on patients' confidence to manage transitions from acute care many will be repatriated to local hospitals and discharged home to community services. Future projects could explore the opportunities and challenges of a self-management approaches integrated into the whole trauma pathway to reduce the loss of continuity and provide benefit for patients and families.

\section{CONCLUSION}

The findings from this improvement project suggest that it was feasible to integrate self-management support in an acute major trauma setting and change AHPs knowledge, attitudes and behaviours regarding person-centred self-management support in the short term. Facilitators included methods to co-design key communication methods and integration of key principles into organisational processes, such as key workers, shared paperwork and joint goal setting.

However, the change was not fully sustained at 6 months, and more attention to methods of engagement prior to training and co-designing ongoing mechanisms from the outset is required. A key challenge to embedding self-management support in this context was the need for whole MDT training to develop a shared understanding and ethos. This requires new ways to engage nursing and medical staff in multidisciplinary training early in the process. We also strongly advocate for patients and families with trauma to be more closely involved with training and their responses included in evaluation methods.

Acknowledgements The authors acknowledge the therapies department at St George's University Hospital, NHS Foundation Trust, London, UK, for funding the project, and physiotherapists Claire Salisbury and Catherine Gray for their assistance with project management. We thank Heide Pöstges from Bridges SelfManagement for commenting on the manuscript.

Contributors FJ and LH contributed to the project concept, design, acquisition of data, analysis of data and critical review of the manuscript. FJ is responsible for the overall content as guarantor. LS and PM-T contributed to the drafting and critical revision of the manuscript. All contributors reviewed the manuscript.

Funding St George's University Hospital, NHS Foundation Trust, London, UK, funded the project. 
Competing interests $\mathrm{FJ}$ is the founder of the social enterprise Bridges SelfManagement. She has not received any financial support for this work that could have influenced its outcome.

Patient consent for publication Not required.

Provenance and peer review Not commissioned; internally peer reviewed.

Open access This is an open access article distributed in accordance with the Creative Commons Attribution Non Commercial (CC BY-NC 4.0) license, which permits others to distribute, remix, adapt, build upon this work non-commercially, and license their derivative works on different terms, provided the original work is properly cited, appropriate credit is given, any changes made indicated, and the use is non-commercial. See: http://creativecommons.org/licenses/by-nc/4.0/.

\section{REFERENCES}

1. National Audit Office. Major Trauma in England. The Stationary Office, 2010. Available: https://www.nao.org.uk/wp-content/uploads/ 2010/02/0910213.pdf

2. National Peer Review Programme. National Peer Review Report: Trauma Services 2015. England: NHS, 2015.

3. National Institute for Health and Care Excellence. Major Trauma: assessment and initial management. National Institute for Health and Care Excellence, 2016. Available: https://www.nice.org.uk/guidance/ ng39/evidence/full-guideline-2308122833

4. Sluys K, Haggmark T, Iselius L. Outcome and quality of life 5 years after major trauma. The Journal of Trauma: Injury, Infection, and Critical Care 2005;59:223-32.

5. Gironda RJ, Clark ME, Ruff RL, et al. Traumatic brain injury, polytrauma, and pain: Challenges and treatment strategies for the polytrauma rehabilitation. Rehabilitation Psychology 2009;54:247-58

6. National Institute for Health and Care Excellence. Patient experience in adult NHS services: improving the experience of care for people using adult NHS services; National Institute for Health and Care Excellence, 2012. Available: https://www.nice.org.uk/guidance/ cg138/resources/patient-experience-in-adult-nhs-servicesimproving-the-experience-of-care-for-people-using-adult-nhsservices-pdf-35109517087429 [Accessed 7 Apr 19].

7. De Silva D. Helping people help themselves: a review of the evidence considering whether it is worthwhile to support self-management. London: The Health Foundation, 2011.

8. Jones F, Brimicombe L. Every interaction counts: The 'Bridges' approach to stroke self-management. Int $J$ Rehabil Res 2014;21:158-9.

9. Ahmad N, Ellins J, Krelle $\mathrm{H}$, et al. Person-centred care: from ideas to action. The London: The Health Foundation, 2014.

10. Morgan HM, Entwistle VA, Cribb A, et al. We need to talk about purpose: a critical interpretive synthesis of health and social care professionals' approaches to self-management support for people with long-term conditions. Health Expect 2017;20.

11. Kulnik ST, Pöstges H, Brimicombe L, et al. Implementing an interprofessional model of self-management support across a community workforce: A mixed-methods evaluation study. J Interprof Care 2017;31:75-84

12. Kidd L, Lawrence M, Booth J, et al. Development and evaluation of a nurse-led, tailored stroke self-management intervention. BMC Health Serv Res 2015;15.

13. Mäkelä P, Jones F, de Sousa de Abreu MI, et al. Supporting selfmanagement after traumatic brain injury: Codesign and evaluation of a new intervention across a trauma pathway. Health Expect 2019;29.

14. de Longh A, Fagan P, Fenner J, et al. A practical guide to self-management support: Key components for successful implementation. The Health Foundation, 2015. Available: http://www. health.org.uk/publication/practical-guide-self-management-support [Accessed 5 Jan 18].

15. Kennedy A, Bower P, Reeves D, et al. Implementation of self management support for long term conditions in routine primary care settings: cluster randomised controlled trial. BMJ 2013;346:f2882.

16. Coulter A, Collins A. Making shared decision-making a reality: no decision about me without me. London: The Kings Fund, 2011.

17. Jones F, Bailey N. How can we train stroke practitioners about patient self-management? Description and evaluation of a pathway wide training programme. EJPCH 2013;1:246-54.

18. Jones F, Mandy A, Partridge C. Changing self-efficacy in individuals following a first time stroke: preliminary study of a novel selfmanagement intervention. Clin Rehabil 2009;23:522-33.

19. McKenna S, Jones F, Glenfield P, et al. Bridges self-management program for people with stroke in the community: A feasibility randomized controlled trial. Int J Stroke 2015;10:697-704.

20. Mäkelä P, Gawned S, Jones F. Starting early: integration of selfmanagement support into an acute stroke service. BMJ Qual Improv Rep 2014;3. doi:10.1136/bmjquality.u202037.w1759

21. Kings College Hospital NHS Foundation Trust and Bridges SelfManagement Limited. The Health Foundation Shine 2014 final report: Early integration of Bridges self-management support package into usual care following traumatic brain injury: a feasibility study, 2015. Available: http://www.health.org.uk/sites/health/files/Kings_Bridges_ Shine\%202014\%20final\%20report_website_version.pdf [Accessed 28 Nov 2016].

22. Jones F, Gage H, Drummond A, et al. Feasibility study of an integrated stroke self-management programme: a clusterrandomised controlled trial. BMJ Open 2015.

23. Jones F. Self-management: is it time for a new direction in rehabilitation and post stroke care? Panminerva Med 2013;55:79-86.

24. May CR, Mair F, Finch T, et al. Development of a theory of implementation and integration: Normalization Process Theory. Implementation Sci 2009;4.

25. Murray E, Treweek S, Pope C, et al. Normalisation process theory: a framework for developing, evaluating and implementing complex interventions. BMC Med 2010;8. 